\title{
¿DERECHA, IZQUIERDA O CENTRO? \\ SOBRE LA LEGITIMACION DE LOS PARTIDOS \\ Y COALICIONES EN EL SUR DE EUROPA * \\ POR
}

GIUSEPPE DI PALMA

En último término, los partidos políticos sirven para gobernar, pero ¿qué partidos tienen derecho a gobernar? Si en muchos países la elección refleja pacíficamente los cambios normales en las preferencias de partido de los electores, las cosas no son tan simples en Europa del Sur. El resurgir de un sistema de partidos luego de decenios de autoritarismo en España y Portugal, el reinicio de la competición partidista después de un breve intervalo de dictadura militar en Grecia, una crisis muy aguda del viejo equilibrio entre partidos y coaliciones en Italia, abren, de hecho, un período de difícil transición y plantean con urgencia el delicado dilema continuismo-ruptura, poniendo así en cuestión la credibilidad para gobernar y hasta la legitimidad de muchos partidos, así como de los sistemas de partidos y, por ello, de las coaliciones de gobierno que ellos expresan. Respecto de estas últimas, podemos ofrecer dos criterios de clasificación, en los que apuntamos opciones y consideraciones fundamentales: el objeto del primero y sincrónico es la composición, el ámbito y la colaboración especial a través del espectro partidista de una coalición de gobierno determinada. El objeto del segundo y diacrónico es la existencia o la ausencia de la alternancia de las coaliciones. Los dos criterios, si los reunimos, nos suministran cuatro formas de gobernar (fig. 1), comprendidas entre dos extremos ideales: gobierno de coalición y por tiempo indefinido, y gobierno separado y por turno.

* Este artículo es una versión revisada de la ponencia presentada al congreso «The Politics of Mediterranean Europe», International Political Science Association y Greek Political Science Association, Atenas, 28 mayo-1 junio 1978. Publicado primeramente en la Rivista Italiana de Scienza Politica, núm. 2, 1978. Agradezco vivamente a George Mavrogordatos las amplias sugerencias y críticas sobre el caso griego. La segunda parte de este artículo se publicará en el núm. 6 de esta revista. 


\section{Figura 1}

\section{CRITERIO DIACRONICO}

Gobierno por turno Gobierno en el tiempo

\begin{tabular}{|c|c|c|c|}
\hline \multirow{3}{*}{$\begin{array}{l}\text { CRITERIO } \\
\text { SINCRONICO }\end{array}$} & \multirow[b]{2}{*}{$\begin{array}{l}\text { Gobierno } \\
\text { por separado }\end{array}$} & \\
\hline & & Alternancia bipartita & Gobierno gaullista \\
\hline & $\begin{array}{l}\text { Gobierno } \\
\text { de coalición }\end{array}$ & $\begin{array}{l}\text { Coaliciones } \\
\text { derecha-izquierda }\end{array}$ & Coaliciones sincréticas \\
\hline
\end{tabular}

Teniendo en cuenta que ninguno de los cuatro modelos de la figura 1 es internamente homogéneo, nos encontramos ante una amplia selección de panoramas: según quien forme parte del Gobierno y quien no; según la exacta extensión espacial y temporal de las coaliciones; según su situación en el centro, en la derecha o en la izquierda, y según la continuidad o innovación en la composición o en las políticas de un nuevo Gobierno.

Volviendo a la Europa del Sur, la cuestión que queda abierta ante el especialista de la ciencia política es qué esquemas pueden ser implantados en cada uno de nuestros países. Cuestión de no fácil respuesta, bien porque cada escenario posee una configuración propia de partidarios y detractores con estrategias y recursos de difícil cálculo, ya porque algunos de los esquemas, aun habiendo sido ya experimentados, han dado, sin embargo, resultados inseguros hasta el momento, ya porque los mismos tipos de partidos y de élites pueden optar por esquemas diversos en países diferentes.

En cuanto a la preferencias de los partidos, se tiende a menudo a atribuir a los partidos comunistas del Mediterráneo una preferencia por las coaliciones amplias y sin alternancia, con el fin de adquirir credibilidad y protegerse de riesgos contraproducentes. Se comprende así la reciente declaración de Santiago Carrillo, más berlingueriano que Enrico Berlinguer, al diario El País:

«Una de las cosas que más me preocupa es que si hay elecciones generales... y si la izquierda se une puedan formar un Gobierno y gobernar contra el centro. España no está todavía madura para una alternativa de derecha e izquierda en el Gobierno. Un hecho de este tipo pondría en peligro todo el proceso democrático» ${ }^{\text {. }}$

Pero ni la UCD (Unión de Centro Democrático), guiada por el primer ministro Suárez, ni nuestra DC (Democracia Cristiana), en lo que le es posible, ven en los partidos comunistas un aliado constante en sus planes de gobierno. $\mathrm{Ni}$ los esquemas de las grandes coaliciones son, por otra parte, comunes a todos los partidos comunistas, y encuentran escaso eco entre los comunistas portugueses y en el Partido Comunista de Grecia (KKE) —el más fuerte de los dos partidos comunistas griegos.

${ }^{1}$ El País, 22 de enero de 1978. 
Los partidos del centro y de la derecha nos ofrecen, por su parte, un variado catálogo de tipos de gobierno, con posibilidades que van desde la histórica inclinación de la DC hasta coaliciones amplias y duraderas abiertas a la izquierda democrática, hasta la apuesta gaullista hecha por la Nueva Democracia de Karamanlis para gobernar en solitario. Pero las posibilidades no cambian solamente de un país y de un partido a otro, sino dentro de cada partido. Así, si en Italia la DC no se encuentra tan inmóvil y unida como antes en sus opciones de coalición, opciones a las que no siempre han respondido sus viejos aliados del centro; si en España la UCD se mueve entre la tentación de un cara a cara con los socialistas del viejo PSOE, la propuesta de coaliciones de centro a la italiana, abiertas a los partidos regionales moderados, y las solicitudes de una gran derecha abierta al continuismo de Alianza Popular y de sus dirigentes ex franquistas, los partidos portugueses del centro-derecha tienen, análogamente, poco que repartir en cuanto a fórmulas de gobierno (divididos como se encuentran los unos de los otros y dentro de cada uno de ellos) entre las hipótesis de coaliciones con un fuerte partido socialista y a la espera de un relanzamiento moderado o quizá reaccionario.

Sólo los socialistas parecerían, al menos comparativamente y a primera vista, firmes y unidos en sus opciones, al seguir siendo la alternativa de izquierda, pese a la reciente derrota de sus parientes franceses, su última posibilidad. Pero se trata de una posibilidad a largo plazo, que revela en seguida diversos grados de persuasividad, según se trate de socialistas españoles y griegos -en ventaja repecto a sus propios comunistas-, en un papel de oposición en condiciones de superioridad numérica, en un contexto de reconocimiento democrático; según se trate de los socialistas del PSI que han sufrido la crisis actual y el predominio comunista sobre la izquierda, o se trate de los socialistas portugueses obligados a gobernar, primero en minoría y después en coalición, con el Centro Democrático Social (CDS) - partido de centro-derecha-, en difíciles condiciones de estancamiento político y social y de recesión de las agitaciones y veleidades de la revolución de los claveles.

Las mismas coaliciones de gobierno, puestas a prueba durante el presente período de transición, confirman la ambigüedad y la incertidumbre de los esquemas mencionados. Se trata realmente de coaliciones de transición y, por tanto (según Almond y sus colaboradores), de coaliciones más «reinantes» (con tareas de mera gestión) que «gobernantes» ${ }^{2}$; se trata de coaliciones demasiado limitadas para durar o demasiado amplias para decidir. Por ello, incluso en el caso italiano, donde los acuerdos de coalición que siguieron a las elecciones de junio del 76 pudieron sugerir un progreso lineal hacia grandes coaliciones omnicomprensivas, las extrapolaciones para el futuro son, en mi opinión, prematuras.

La finalidad de los ejemplos antes referidos no es confundir y desanimar al lector, sino advertirle, si ello es necesario, de dos cosas:

1. La complejidad de preferencias de coalición, de los acontecimientos y de las «falsas salidas» en la Europa del Sur no es un hecho genérico de los

\footnotetext{
${ }^{2}$ Sobre coaliciones reinantes y gobernantes, cfr. G. Almond y otros, Crisis Choice, and Change, Boston, Little, Brown, 1973.
} 
sistemas competitivos pluripartidistas, sino un hecho propio de las coaliciones inaugurales o de crisis. Dejando al margen el hecho de que la presencia de más de dos partidos en los parlamentos de nuestros cuatro países sustrae la formación de Gobierno al control exclusivo de los electores, abriendo la puerta a coaliciones interpartidistas, resulta, sin embargo, cierto que la continua atención a las aperturas, alianzas y delimitaciones - la constante preocupación no sólo de quien gobierna, sino sobre todo de quien está legitimado y cómorefleja con más exactitud el hecho de que el Mediterráneo está hoy en día implicado en un difícil proceso de inauguración, relanzamiento o regresión radical de los regímenes competitivos. Puesto que por encima de estos acontecimientos se encuentra una larga experiencia autoritaria o una crisis sin precedentes de los partidos que han controlado hasta ahora el régimen competitivo, se deduce que lo que está en juego es nada menos que el tema de la legitimaciónrelegitimación; y dado que en los regímenes competitivos los partidos políticos y los sistemas de partidos son las estructuras clave, reconocidas y visibles, para sancionar los gobiernos, la legitimación-relegitimación afecta al espectro político -especialmente en momentos excepcionales caracterizados por la atención colectiva-. Lo que, en último término, nos permite afirmar que hasta que no se delimite con precisión la composición, perfil electoral y distribución ideológica de los sistemas de partidos el juego de las coaliciones continuará sin solución - síntoma y factor de una difícil transición.

2. Por tanto, el juego de las coaliciones inaugurales, y con ello la fijación o delimitación de los sistemas de partidos, resultan, por una parte, inciertos e inconstantes y, por otra, de una importancia decisiva en ciertos aspectos ${ }^{3}$. En cuanto a la incertidumbre, ¿quién habría apostado seriamente a la muerte de Franco sobre la rápida evolución hacia un sistema abiertamente competitivo?, y ¿quién habría podido vaticinar, antes de la decisión de Suárez de aceptar la dirección de UCD, la rápida y holgada victoria electoral del partido a los pocos meses de los Pactos de la Moncloa?

¿Quién habría podido anticipar, ante los acontecimientos de la revolución portuguesa, los altibajos de la fortuna en los movimientos de las Fuerzas Armadas y el éxito final de los socialistas de Soares? Y ¿quién esperaba la súbita caída de los coronoles griegos y la decisiva toma del poder por parte de Karamanlis? Y ¿quién, vistos los resultados de las últimas elecciones italianas, habría previsto la estrategia escogida por la DC para mantenerse en el poder?

El hecho es que en la formación de una nueva coalición, quizá dentro de un nuevo marco de autoridad, da buen juego el equilibrio de las fuerzas contendientes en el momento de la transición, con consideración especial a la forma en que dichas fuerzas consigan aprovecharse de la dinámica, a menudo

${ }^{3}$ Hasta tal punto que Gabriel Almond y sus colegas han dedicado un volumen íntegro al tema de las coaliciones inaugurales, ibid., y Philippe Schmitter ha centrado un reciente análisis del Portugal post-Caetano sobre conceptos análogos (P. Schmitter, Historical Bloc Formation and Regime Consolidation in post-Autboritarian Portugal, noviembre 1976, ciclostilado). Un análisis hoy clásico del papel fundamental de la fase inaugural en la constitución del sistema participado se encuentra en G. Loewenberg, Tbe Remaking of the German Party System, en M. Dogan y R. Rose (eds.), European Politics, Boston, Little, Brown, 1971, págs. 259-279. 
rápida, de la transición. Es decir, el hecho de que las crisis de coaliciones y, más aún, las transiciones de régimen vayan acompañadas de una deflación de poder y de una aceleración y acumulación de acontecimientos frecuentemente imprevisibles, confiere al azar un papel que es absolutamente inusitado en condiciones de estabilidad. Y cuando los acontecimientos son aleatorios, cuando los políticos y los expertos tienen que recurrir a informaciones limitadas y distorsionadas, cuando el cálculo de los riesgos siempre se hace con criterios racionales y universales, resulta una tarea difícil predecir en qué dirección se moverán regímenes y coaliciones, a menos que uno se encuentre literalmente encima de los acontecimientos.

Pero la incertidumbre no significa que las transiciones y crisis tengan consecuencias de escaso relieve; por el contrario, significa que desarrollos en la naturaleza de los regímenes de coaliciones y de los sistemas partidistas, que en un análisis retrospectivo podrían parecer preconizados y ordenados por las cadencias necesarias de la historia, revelan además (si no exclusivamente) la impronta de hechos específicos y temporalmente circunscritos que «desvían» la historia ${ }^{4}$.

Dicho esto, nos encontramos inmovilizados ante un dilema poco fructífero: esperar prudentemente que los acontecimientos sigan su curso, dado que de todas formas son más bien insondables, y «predecir» después retrospectivamente (empresa de ningún modo insignificante, pero que comporta el riesgo de otorgar un peso excesivo a las soluciones de emergencia y de atribuir valor de la necesidad preordenada a nuestras explicaciones) ${ }^{5}$; o afrontar valerosamente los hechos cotidianos, dado que son cruciales, con el riesgo de hacer periodismo, desmentido finalmente por los hechos. Tras haber discutido ampliamente el dilema con motivo de la interpretación del caso portugués, Philippe Schmitter opta por un examen directo y en caliente de los contextos y contenidos, dentro de los cuales los políticos portugueses llevan a cabo su investigación sobre una coalición inaugural ${ }^{6}$.

Por mi parte, he tratado de evitar en otro trabajo el dilema distanciándome de los acontencimientos de la transición en el área mediterránea, sin negar por esto la importancia de acontecimientos similares en otros contextos. He justificado esta toma de distancia en un ensayo sobre Italia, Portugal y España, escrito a principios de 1977, sugiriendo, en efecto, que nuestros regimenes sufrirán en el futuro un problema recurrente de legitimidad, problema que hunde sus raíces en las crisis y en los cambios políticos ocurridos en los tres países, y que los acontecimientos de la transición tienen escasa posibilidad de solucionar ${ }^{7}$. A falta de un apoyo de las masas difuso y desinteresado, por decirlo adoptando la terminología de David Easton, y de una suficiente iden-

- Para una discusión de las crisis, transiciones y revoluciones como campos decisivos del conflicto de grupo, cfr. C. Tilly, Revolutions and Collective Violence, in F. Greenstein and N. Polsby (eds.), Handbook of Political Science, vol. 3, Reading, Mass. Addison-Wesley, 1975, cap. 5.

${ }_{5}$ R. Bendix, Tradition and Modernity Reconsidered, en R. Bendix, Embattled Reason, Nueva York, Oxford University Press, 1970.

${ }^{6}$ P. Schmitter, Historical Bloc Formation, cit.

7 G. di Palma, Italia, Portogallo, España: Hipotesi su tre regimi alla prova, en «Prospettive Settanta», 3, febrero-marzo 1977, págs. 41-62. 
tificación institucional, he mantenido que nuestros regímenes se verán empujados a adoptar medidas mediante la búsqueda de amplias plataformas de apoyo instrumental ${ }^{8}$. Para encontrar además la fórmula de coalición gubernativa adecuada para la creación de condiciones para este apoyo, los partidos de la Europa latina —añadía - no tendrán que buscar demasiado lejos, pudiendo confiar en las fórmulas de coalición que - con variaciones significativas, según se trate de regímenes autoritarios, liberales o democráticos- nuestros regímenes han compartido en los últimos cien años. La fórmula no admite ni coaliciones en competencia de mercado, como en el modelo clásico de Anthony Downs ${ }^{9}$ (no, ciertamente, en regímenes autoritarios, pero tampoco en períodos liberales y democráticos), ni la dictadura totalitaria y sin residuos del partidoclase (no, ciertamente, bajo los regímenes liberales y democráticos, pero tampoco en períodos autoritarios) ${ }^{10}$. La fórmula se basa más en coaliciones amplias e incluyentes que se perpetúan en el poder, a pesar de la presencia de frecuentes remodelaciones, gracias a la cooptación política de intereses heterogéneos, tendiendo así a absorber el conflicto y a extender, diversificando, la penetración del régimen y de los partidos. En su versión democrática competitiva, la fórmula aparece abajo, a la derecha, en la figura 1. Esta predisposición histórica para las combinaciones no refleja un rasgo cultural genérico de los políticos latinos (la fine Italian band, como dirían los anglosajones), sino más bien una respuesta - ambigua y funcional si se quiere-a a un problema recurrente de legitimidad, o del principio de autoridad de los regímenes o de las fuerzas políticas que ocupan en ellos los núcleos centrales.

Este modelo de respuesta mediante la coalición ejerce su influencia sobre el futuro de nuestros regímenes, introduciéndonos, concluía yo, en el ámbito de las confining conditions -en palabras de Otto Kirchkeiner-, es decir, de límites e incentivos no sólo del período actual de transición, sino, sobre todo, una vez finalizada ésta, en la fase de consolidación e institucionalización ${ }^{11}$.

Pero ¿cuál es el peso específico de las mencionadas confining conditions? Una atención excesiva a las mismas y a los precedentes históricos puede evitarnos el riesgo de ser arrastrados por la vorágine de los acontecimientos, pero a costa de una posible falta de atención a las condiciones favorables a una ruptura con los modelos del pasado. ¿El momento presente carece verdaderamente de las condiciones y ocasiones favorables a la legitimación de partidos y coaliciones? El tema sigue aún abierto. No debe descuidarse el hecho de que la estrategia y los acontencimientos, propios de la transición, tienen (tanto desde las perspectivas de la política como especialmente desde el punto de vista de las identificaciones y satisfacciones simbólicas) un efecto notable sobre la fuerza de los partidos y sobre la composición de gobiernos y coaliciones,

8 D. Easton, A Framework for Political Analysis, Englewood Cliffs, Nueva Jersey, Pretince-Hall, 1965.

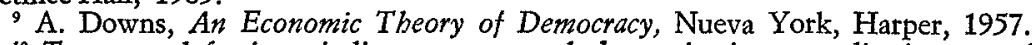

1o Tampoco el fascismo italiano - a pesar de las aspiraciones totalitarias en realidad inconsistentes en regímenes como los de Franco, Primo de Rivera, Salazar, Metaxas o de los coroneles griegos- trató nunca de imponerse como dictadura de un solo partido.

"O. Kircheimer, Confining Conditions and Revolutionary Breaktbroubgs, en «American Political Science Review», 49 (1965), págs. 964-974. 
formen parte de las coaliciones o las dominen socialistas, laicos moderados, comunistas, católicos o elementos de derecha. De ello resulta que la composición de los partidos y la distribución de influencias y de las expectativas, dentro y fuera de las coaliciones de transición, determinan, por su parte, una gran diferencia en lo que respecta al problema de la legitimidad y, por ende, al tipo de coaliciones y gobiernos que tenderán a formarse y a caracterizar de forma estable a los regímenes una vez finalizada la transición.

En particular el problema es si nuestros regímenes pueden salir de la transición, y gracias a ella con un sistema, por lo menos en potencia, de alternativa creíble que no divida la sociedad - señal de que la legitimación del sistema partidista ha tenido éxito-, o si se verán impulsados hacia fórmulas de coalición centrista sin alternativa o, análogamente, hacia gobiernos dominados a lo largo del tiempo por un solo partido, unión o federación política. Para decirlo con otras palabras, si el uso de fórmulas inspiradas en la gran coalición durante un período limitado de la transición puede favorecer el proceso de legitimación, la continuación de las mismas en una fase de estabilidad puede significar que el proceso ha fracasado, y lo mismo puede decirse en ciertos casos si un partido-unión-federación, aunque cuenta con el apoyo de los electores (ésta no es la cuestión), continúa por tiempo indefinido en la dirección del Gobierno.

Además de las estrategias de coalición, otros hechos de la transición pueden desempeñar un papel en la formación y legitimación de partidos y sistemas de partidos, en definir el lugar ocupado por los partidos en el Gobierno local y nacional y, en consecuencia, en el establecimiento de fórmulas futuras de coalición; hechos como el proceso constitucional, la adopción de normas electorales, la reestructuración de las autonomías locales y de las relaciones entre el centro y la periferia, la formación de la imagen de los partidos, así como de sus alianzas y de las estrategias de presencia social e institucional ${ }^{12}$. Por tanto, merece la pena considerar desde más cerca el análisis de la transición en nuestros países, teniendo al menos in mente la posibilidad de soluciones distintas de país a país.

\section{LAS TRANSICIONES ACTUALES}

No creo forzar la lectura de los acontecimientos si sugiero que uno de los aspectos que más llama la atención en las transiciones en curso es la presencia, al menos entre aquellas fuerzas que más genuinamente aspiran a soluciones de tipo pluralista y competitivo, de una profunda conciencia de la importancia que adquieren en la transición los problemas de la legitimidad y de la estabilidad, de su estrecha conexión y de la complejidad de las soluciones; conciencia hoy en día agudizada por el hecho de que la solución adoptada después de la guerra en Francia e Italia (un sistema parlamentario «racionalizado» con partidos organizados y programáticos) no ha dado buen resultado (Cuarta República francesa), aun cuando ha sido mantenida por la presencia de un par-

${ }^{12}$ Dado el tema de este ensayo, el acento recae sobre el papel de los partidos en la transición. Menor (o indirecto) relieve se atribuye al papel de los «grands corps», sindicatos, organismos constitucionales, iglesias, presidente y primer ministro y órganos transicionales expresamente constituidos. 
tido predominante en el Gobierno (Italia). Decir, sin embargo, que existe conciencia del problema no es decir mucho sobre tratamiento, soluciones y perspectiva, dado que, para empezar, existen diferentes planteamientos e intentos de solución en lo que respecta a opciones, límites, prioridades y urgencia, según se trate de uno u otro país o partido.

La causa de esta diversidad no debe buscarse, en mi opinión, en los diversos orígenes de la transición: la caída de los viejos regímenes autoritarios que habían hecho «tabla rasa» del sistema competitivo en Portugal y España; la revocación de un breve régimen militar de excepción, en Grecia; una crisis del sistema de coalición, en Italia. Aunque macroscópicas, estas diferencias reflejan sólo imperfectamente aquélla que considero, para nuestros efectos, la variable central de la transición, es decir, la extensión y variedad de las fuerzas políticas que demandan encontrar un lugar y ser reconocidas en el marco político futuro o que, por el contrario, pueden resultar marginadas impunemente.

La variable (que no dejo aún de reconocer como poco homogénea) contiene dos vectores. El doble problema consiste en si las condiciones de la transición son tales como para exigir espacio para las viejas fuerzas políticas (o como para permitir una ruptura con las mismas) y si al mismo tiempo nuevas fuerzas políticas (habitualmente partidos de izquierda) solicitan con credibilidad inminente su participación en el Gobierno. Depende a su vez de la amplitud y diversidad de las fuerzas que exigen un lugar en el nuevo orden político, así como de la credibilidad de sus demandas, si los actores políticos implicados en la transición se verán en distinta forma obligados, motivados o (serán) capaces de adoptar estrategias de tipo consensual; estrategias que producirán luego sus efectos sobre la legitimación final del sistema de partidos y del tipo de coaliciones que resulten de la transición. Es útil repetir que todo esto tiene poco que ver con el hecho de que el régimen que preceda a la transición sea autoritario o democrático; tan es así que los países más semejantes en la gestión de la crisis son Italia y España, casos de los que me serviré para establecer la comparación con Grecia y Portugal.

\section{ITALIA Y ESPAÑA: TRANSICION Y TRANSACCION}

En estos dos países, como respuesta al amplio espectro de fuerzas políticas que demanda verosímilmente una regulación del nuevo orden, la transición ha adoptado, utilizando un juego de palabras, la forma consensual de una «transición por transacción».

Italia. En Italia la crisis iniciada en 1969 tiene lugar en un régimen con treinta años de experiencia democrática, en muchos aspectos positiva, y con una serie de partidos (incluido un prudente partido comunista) que, a pesar de los reiterados enfrentamientos ideológicos en el campo electoral, que han desarrollado, a lo largo de los años y en varios contextos institucionales, una notable capacidad de intercambio y convivencia política ${ }^{13}$. Capacidad que tien-

${ }^{13}$ Sobre este punto, véase el más reciente de D. di Palma, Surviving Witbout Governing: the Italian Parties in Parliament, Berkely, University of California Press, 1977, trad. 
de a reafirmarse en el momento de las elecciones del 75 y del 76, luego de un largo período de deflación del poder de los partidos y de pérdidas del control sobre los movimientos y sobre la sociedad civil, agravado por la crisis irreversible de la fórmula de centro-izquierda ${ }^{14}$.

Una razón para la adopción progresiva de estrategias de transición es que la crisis, por ahora, es sólo una crisis de las fórmulas de coalición; crisis que, si bien carece de precedentes por su gravedad, en tanto pone en cuestión treinta años de gobiernos «sincréticos» dirigidos por el centro de la Democracia Cristiana, no afecta todavía al marco democrático. A diferencia de lo que sucedió en la crisis prefascista, pocos están hoy dispuestos a convertir sus críticas al modo en que la democracia parlamentaria se practica en Italia en una acusación al mismo concepto de democracia; y pocos buscan la solución en una derrota del mayor partido del Gobierno. $Y$ dado que la DC, a pesar de ataques e insultos, conserva su fuerza electoral, que, no obstante, lo ha conseguido a costa de sus aliados menores, mellando la función de comodín de éstos; que esto ha dejado al PCI, el otro vencedor de las elecciones de 1976, enfrentado a la DC, replanteando con urgencia final el problema de quién gobierna; que el crecimiento del PCI parece además unido a tendencias generacionales y de realineamiento electoral de no inmediata reabsorción ${ }^{15}$; pero, finalmente, dado que el comunismo italiano padece aún un problema de credibilidad democrática y de gobierno, se infiere que para salir del impasse DC y PCI tienen interés en convergencias de coalición y en soluciones transadas - por muy difíciles y aun improbables que puedan revelarse ${ }^{16}$.

Los propios partidos menores, no obstante los evidentes peligros para su función de gobierno y hasta para su supervivencia, y no obstante su preferencia a largo plazo por estrategias de alternancia, no pueden sustraerse fácilmente al influjo del marco de rapprochement DC-PCI. De la misma forma que han apoyado al Gobierno de las abstenciones de Andreotti después de las elecciones de junio de 1976 y del acuerdo programático de julio de 1977, también han prestado su conformidad al ingreso formal de los comunistas en la mayoría parlamentaria de marzo de 1978 . No podemos ignorar el importante, aunque no necesariamente decisivo, papel que los factores internacionales desempeñan en la adopción de estrategias transaccionales. En un país con la situa-

italiana, Sopravvivere senza governare, Bolonia, Il Mulino, 1978, y S. Tarrow, The Italian Party System Between Crissis and Transittion, en «American Journal of Political Science», XXI (1977), págs. 193-224.

${ }_{14}$ Para un análisis de las varias fases y del cambio de marco implicados en la crisis de la democracia, véase J. Linz, Crisis, Breakdown and Reequilibration of Competitive Democracies, en J. Linz y A. Stepan (eds.), Breakdown and Crisis of Democracies (en prensa). El análisis se inspira en el estudio de K. D. Bracher sobre la caída de la República de Weimar, y ha sido usado por Paolo Farneti para examinar la caída del liberalismo en la Italia prefascista. Véase P. Farnet, La crisi della democrazia italiana e l'avvento del fascismo: 1919-1922, en «Revista Italiana de Ciencia Política», V (1975), págs. 45-82.

${ }_{15}$ G. Sani, The PCI at the Tbresbold, in «Problems of Communism», XXV, noviembre-diciembre 1976, págs. 27-51. Se trata de uno de los numerosos estudios de Sani dedicados al origen de realineamiento del partido en Italia.

${ }_{16}$ Un tratamiento más extenso de todos estos puntos se encuentra en G. di Palma, Political Syncretism in Italy: Historical Coalition Strategies and the Present Crisis, Policy Papers, en «International Affairs», Berkeley, Institute of International Studies, 1978. 
ción geopolítica de Italia, la apertura hacia la DC, así como la adhesión a la Alianza Attántica y a la Comunidad Europea sirven al PC para protegerse de ingerencias externas y para consolidar su propia credibilidad.

España. Si en España la transición implica un paso más radical hacia una nueva fórmula constitucional, ello no significa, sin embargo, que la inauguración de la democracia, incluso liberando nuevas fuerzas políticas de notable entidad, se haya resuelto en una derrota de las viejas fuerzas organizadas en torno al franquismo. No prueba lo contrario la casi nulidad de las fracciones más abiertamente nostálgicas y estridentes del régimen (Fuerza Nueva, FE de las JONS, FEA), demostrada en el referéndum de diciembre de 1976 sobre la Ley de Reforma Política y en las elecciones de junio de 1977. Ciertamente, un simple hecho, la muerte natural de Franco ha demostrado su carácter resolutivo, abriendo por sí solo la caja de Pandora de los trastos viejos y rémoras del régimen y de los resentimientos, los cuales, nutridos por la situación de España en un contexto europeo, ni la violencia de Estado ni los halagos de un pluralismo limitado de impronta autoritaria conseguían asimilar. Sin embargo, dada la edad y la salud vacilante, la muerte de Franco era un hecho previsto, y si el régimen no estaba preparado tampoco fue sorprendido por ella. Dado el personalismo desatado de Franco, el acontecimiento elimina el símbolo, clave que mantenía unidos los diversos principios de legitimidad - jamás fusionados-, sobre los que se basaba el régimen autoritario. Igualmente elimina al árbitro de última instancia de las tensiones entre los grandes intereses ${ }^{17}$. Pero deja vivos los automatismos propios del Gobierno y las estructuras burocráticas, militares y periféricas. El régimen no se había dejado envolver durante los últimos años en aventuras desestabilizadoras y ruinosas del tipo de las que clásicamente anuncian la caída de los regímenes autoritarios: una guerra internacional (Mussolini), una guerrilla colonial (Salazar y Caetano), un conflicto territorial (los coroneles griegos). Por el contrario, Franco había recurrido a una serie de nombramientos y de tímidas medidas liberalizadoras, especialmente en la segunda parte de los años sesenta, para afrontar a su modo el doble problema de la continuidad personal e institucional:

1. Investidura de Juan Carlos como futuro rey (1969) y nombramiento de Carreto Blanco como jefe del Gobierno (1973) ${ }^{18}$.

2. Liberalización de la legislación sobre la prensa (1967).

3. Reconocimiento limitado de la contratación colectiva (1958) y del derecho de huelga (1966-1967) en materia económica.

4. Elección de aproximadamente un 20 por 100 de las Cortes por parte de los cabezas de familia y mujeres casadas (1967).

${ }^{17}$ No es necesario decir que, para el análisis de las características del régimen (pluralismo limitado, personalismo, legitimidad, etc.), me ha sido muy útil el trabajo de Juan Linz. Sobre el papel de Franco, de su «familia política» y de su gobierno, en el proceso de decisión político-burocrático, véase también R. Gunther, Spanisb Budgetary Politics, tesis doctoral, Berkeley, Universidad de California, 1977.

${ }_{18}$ Cabe preguntarse qué habría sucedido en España después de Franco si Carrero Blanco no hubiera sido asesinado en diciembre de 1973. 
5. Reconocimiento y regulación de las «asociaciones políticas» dentro de los principios del Movimiento (1974) ${ }^{19}$.

Todo esto ha hecho bastante difícil el aislamiento de aquellas fuerzas políticas ligadas o comprometidas en alguna forma con el franquismo que, al reemprender la vida democrática, se mostrasen dispuestas a participar en el nuevo juego competitivo ${ }^{20}$. España a la muerte de Franco no es, después de todo, la Italia de después de Mussolini, cuando las responsabilidades de la guerra y la experiencia de la resistencia facilitaron e impusieron la depuración de las fuerzas fascistas y parafascistas. Al mismo tiempo, si el curso de los acontecimientos en España impide una clara ruptura con un pasado de cuarenta años - tanto es así que cuadros locales y nacionales comprometidos con el viejo régimen se encuentran no sólo en Alianza Popular, la federación de partidos fundada por Fraga Iribarne y otros miembros frondistas de los gobiernos de Franco, sino también en el partido del Gobierno-, dicho devenir ciertamente no impide la consolidación de nuevas fuerzas políticas con credenciales antifranquistas más firmes. De hecho, son las mismas medidas liberalizadoras adoptadas por Franco, siguiendo el principio de cambiar algo para que nada cambie, las que ayudan a su formación. Basta pensar en la posibilidad de organización y de presencia en las fábricas ofrecida a Comisiones Obreras por la liberalización de la legislación laboral y de la contratación colectiva. Por otra parte, tanto en Portugal como en España, decenios de política sin partidos, parecen haber hecho poco o nada por atenuar la afición por los partidos y las etiquetas ideológicas, reverdecidos por el entusiasmo colectivo de la liberalización.

Pero la amplitud y diversidad de las fuerzas políticas implicadas en la transición no son suficientes para explicar por qué todos los partidos de cierta entidad, desde Alianza Popular al PCE, favorecen, o al menos toleran, un proceso consensual de apertura democrática. En efecto, el que la diversidad engendre el consenso puede parecer más bien ilógico, a menos que no se tenga in mente la aguda conciencia de los peligros de exclusiones recíprocas demostrada por varias fuerzas políticas y su voluntad de «aprender de la historia». Así como en Italia los partidos políticos son hoy conscientes del precio pagado por el país por las exclusiones recíprocas y por los errores de coalición durante la crisis prefascista, en España las élites locales, sensibilizadas además por el caso italiano, recuerdan los errores de la Segunda República, errores que, luego de un restringido proceso constitucional dirigido a crear una «república para los republicanos» y luego de un continuo movimiento de gobiernos recíprocamente aborrecidos, desembocaron en la guerra civil ${ }^{21}$.

${ }^{19}$ A propósito de esta reforma y de su relación con la sucesiva apertura democrática, véase L. Morlino, Dal pluralismo limitato al pluralismo competitivo. Partiti e Sindicati, en G. de Vergottini (a cargo de), Una Constitución democrática para España, Milán, Franco Angeli, 1978, cap. 5.

${ }_{20}$ Debo aclarar que lo que trato de explicar no es tanto el porqué, contrariamente a toda expectativa, después de la muerte de Franco se ha reiniciado el juego democrático, sino simplemente el porqué, dando esto por descontado, dicho juego democrático cubre un espectro amplio, de derecha e izquierda, de fuerzas democráticas.

${ }^{21}$ El hecho de que las exclusiones recíprocas en la Segunda República implicaran entonces una dosis considerable de errores de juicio y de miedos internos (o de asunciones 
Existe, naturalmente, una diferencia inicial importante entre la inauguración de la vieja República y la que está en marcha. La primera estaba en manos de los partidos socialistas y republicanos, mientras que la segunda ha sido dirigida desde el comienzo por elementos que provienen del régimen franquista: en particular un rey escogido por Franco y en estrecha relación con las Fuerzas Armadas, y un Gobierno que, aunque abierto gradualmente a elementos demasiado jóvenes para estar comprometidos a fondo con el franquismo, acaba, sin embargo, por ser presidido, con la destitución de Arias Navarro ocho meses después de la muerte del dictador, por un ex secretario del Movimiento.

Pero una vez que estas élites se deciden por la vía democrática, la diferencia, de hecho, no se produce en desventaja de la apertura en marcha. Juan Carlos y sus gobiernos están en condiciones de utilizar leyes e instituciones del viejo régimen - que, como en todos los regímenes autoritarios, son polivalentes y reciclables - para conseguir una legitimación «hacia atrás», o legitimación retrospectiva del proceso inaugural. Es decir, si como herederos del pasado apenas pueden permitirse limitar y manipular el nacimiento de nuevos partidos, según revela lo ocurrido en Portugal, se encuentran, sin embargo, en buena posición para sancionarlo y hacerlo aceptable, lo que, a su vez, les permite plantear su propia legitimación hacia adelante.

Es menester, en fin, añadir que un papel importante en el desarrollo de este juego a dos tableros lo desempeñó, particularmente en los meses del referéndum y de las elecciones, el sentido de la oportunidad del Gobierno, la rapidez en la decisión y la capacidad de anticiparse; cualidades insondables, dada su naturaleza, que sólo nos es posible constatar a posteriori. El ejemplo más «habilidoso» del juego de legitimación llevado a cabo por el Gobierno es la gestión del referéndum sobre la Ley de Reforma Política; referéndum que, sancionado en la previa aprobación de la ley por las Cortes franquistas y tímidamente boicoteado por algunos de los nuevos partidos democráticos - por razones idealmente, si no políticamente comprensibles, dado que la Ley de Reforma fue «impuesta» y que el procedimiento de legalización de los partidos no fue acabado-, se resolvió en una aprobación casi plebiscitaria de la hipótesis democrática y en una victoria personal del primer ministro. La decisión de Suárez de asumir la presidencia de UCD, formación política descoyuntada y dispersa, se reveló, en fin, decisiva, aunque fuera adoptada in extremis para llevar a la UCD a la victoria en las elecciones legislativas de junio de 1977. La principal derrota, e inesperada, fue la de la nostálgica Alianza Popular. Pero incluso el Partido Comunista, reconocido apenas dos meses antes, resultó con menos fuerza de la prevista. El gran antagonista del partido del Gobierno es, por tanto, el Partido Socialista.

La victoria de UCD y la formación de otro gabinete Suárez en la espera del

optimistas de riesgos), puede ser más bien un motivo ulterior de la táctica más cauta adoptada hoy. Queda el hecho de que el contexto histórico y cultural, en el que se producen acontecimientos «similares», puede ser considerablemente distinto y de que la historia no se repite necesariamente. Sobre la apertura democrática en la república española, véase J. Linz, From Great Hopes to Civil War: The Breakdown of Democracy in Spain, en J. Linz y R. Stepan (eds.), Breakdown and Crisis, cit. 
debate sobre la nueva Constitución no significan, sin embargo, un cierre prematuro respecto de los otros dos partidos. Mientras los principales partidos (incluso AP, PCE y Minoría Catalana) forman parte de la comisión ad boc a la que se ha confiado la tarea de una primera redacción del texto constitucional, los Pactos de la Moncloa, firmados en octubre del mismo año, sancionan un amplio acuerdo interpartidista sobre las reformas económicas y cívico-constitucionales más urgentes.

Aunque la descripción realizada sea quizá demasiado optimista, aunque los pactos de octubre hayan sido incumplidos con frecuencia, aunque el Gobierno, luego de los primeros y más difíciles meses, no vaya con escrúpulos en la monopolización de procedimientos e instituciones, la novedad del proceso de inauguración democrática sigue estando intacta: un régimen autoritario es abolido utilizando su propia legalidad, con una estrategia que trata desde el principio de sobrepasar y captar a los partidos que rechazan la herencia autoritaria. La estrategia se basa en dos elementos: tácticamente en el sentido de la oportunidad y de la anticipación, en particular hasta las elecciones parlamentarias; formalmente, en un esfuerzo de retrolegitimación y de legitimación hacia el futuro del nuevo marco constitucional y del sistema de partidos. La legitimación hacia adelante se convierte en predominante al finalizar las elecciones e iniciarse la fase constituyente. Aparte las lógicas y, por otra parte, importantes diferencias, la apertura española me recuerda la fase constituyente en la Italia de la posguerra: referéndum institucional, Asamblea Constituyente. Más tarde examinaremos algunas de las diferencias, entre las cuales una, y prometedora, podría consistir en el hecho de que España tiene hoy en día un número menor de partidos nacionales con representación en el Parlamento. Pero es necesario prestar atención: el que un sistema partidista sea de un pluralismo limitado en cuanto a número no significa siempre - basta en este sentido la opinión de Sartori ${ }^{22}$ - que lo sea respecto a comportamiento.

\section{PORTUGAL Y GRECIA: LOS RIESGOS DE GOBERNAR SOLO}

De lo anteriormente expuesto es prueba el caso de Portugal, donde la presencia de sólo cuatro partidos no ha simplificado nada el proceso de legitimación constitucional y partidística.

Portugal. En Portugal la falta de un planteamiento claro y de un consenso amplio en la gestión de la transición está unida de entrada a la imprevisibilidad y al carácter repentino del acontecimiento que la puso en marcha: el derrocamiento del régimen autoritario y la ruptura de sus alianzas por parte de las Fuerzas Armadas, es decir, por parte de uno de sus componentes. El acontecimiento revela una crisis que no es tanto efecto de la enfermedad incapacitadora de Salazar y de las dificultades de Caetano para adecuar el régimen al

22 Tengo «in mente» la distinción de Giovanni Sartori entre pluralismo partidista limitado y moderado. Más recientemente, véase Sartori, Parties and Party Systems, Cambridge, Cambridge University Press, 1976, cap. 6. 
cambio de guardia, como de una debilidad intrínseca y vieja existente en el equilibrio interno del régimen, agravada, a la postre, por un desplazamiento y caída de los beneficios y de las prerrogativas institucionales a él atribuidas ${ }^{23}$. $\mathrm{Ha}$ ocurrido que las Fuerzas Armadas, y en su nombre los cuadros operativos más jóvenes, ya relativamente marginados del régimen (recuérdense los «cuartelazos» periódicos), han debido sufrir en los últimos años tanto el peso como las culpas de una guerra colonial. Además, deben aceptar la progresiva introducción en los cuadros de los oficiales de carrera, con facilidades especiales para ascender, de milicianos de complemento movilizados por causa de las necesidades coloniales. Son estos resentimientos corporativos, mezclados malamente con ideologías sociomilitares tercermundistas, aprendidas en las colonias por los oficiales del frente, lo que acaba por cebar la revuelta ${ }^{24}$. Pero las Fuerzas Armadas, que a través de los oficiales más jóvenes parecían querer dirigir la transición por sí solas, confiriéndole una ideología y una organización hegemónica, se mostraron después divididas, fragmentadas, entre Europa, América Latina y el Tercer Mundo; entre aspiraciones conservadoras, socialdemócratas, stalinistas y neomarxistas; entre viejos y nuevos generales, capitanes y sargentos; entre las instancias corporativas, arribismos de carrera y de poder, jacobinismos y prefiguración de regeneración total. Todo esto confirma incidentalmente que, puesto que las Fuerzas Armadas poseen el monopolio casi exclusivo de la violencia, es fácil predecir qué dirección tomará una revolución si se sabe dónde y con quién están; más difícil es saberlo si las Fuerzas Armadas se dividen.

Pero, para nuestro análisis, la cuestión importante es que estos sucesos, la caída del régimen y el activismo de los militares, sorprenden a los partidos democráticos portugueses, privados de las sólidas raíces del período republicano que precedió al salazarismo; carecen, después de casi medio siglo de autoritarismo estólido, aislacionista y reaccionario, bien de la limitada experiencia de organización clandestina interior de los partidos españoles e italianos bajo sus respectivos regímenes autoritarios; bien de un espacio circunscrito de acción y de organización en vistas de la recuperación democrática que, a la caída del fascismo, se abrió a los partidos italianos como consecuencia de la guerra y de la resistencia. Aún de mayor relieve es la ruptura por iniciativa del Partido Comunista y del frente de acción común de los partidos democráticos - contrariamente a la experiencia italiana de la resistencia y a la actual española-. Los comunistas portugueses, poco sensibles (por razones que dejaré de lado) a la estrategia tipo svolta di Salerno, descubren en el activismo del movimiento de las Fuerzas Armadas un acontecimiento «afortunado» sobre el que apostar para conseguir en breve plazo y con menores compromisos el resultado que hoy escapa a sus compañeros españoles, como escapó hace treinta años a los italianos. Así, el proceso de legitimación constitucional del nuevo régimen a través de las elecciones democráticas y la Asamblea Constituyente, deseado par-

${ }^{23}$ Para un análisis de la revolución en esta clase, véase P. Schmitter, Liberation by Golpe: «Retrospective on the Demise of Autboritarian Rule in Portugal», en Armed Forces and Society, II (1975), págs. 5-33.

${ }_{24}^{24}$ Esta dinámica de los acontecimientos constituye una interpretación tipo en muchos autores. 
ticularmente por los socialistas, fue, en parte puesto en tela de juicio y vaciado de contenido por la contradictoria estrategia hegemónico-tutelar del MFA y de los comunistas. Al mismo tiempo, la legitimación del sistema de partidos fue recíprocamente truncada por causa, de una parte, de las prevaricaciones comunistas y, de otra, de la etiqueta antisistema colgada, justa o injustamente, a los dos partidos del centro-derecha: el vagamente socialdemócrata Partido Popular Democrático (PPD) y el vagamente democristiano Centro Democrático Social (CDS).

Portugal se encuentra, en fin, obsesionado por un problema de retrolegitimación y, lo que es más grave, por un problema de legitimación futura. Sobre todo en los primeros y más cruciales momentos de la transición, hasta la derrota de los militares radicales en noviembre de 1975, falta un principio consensual de legitimación de la transición, parecido al español actual y al italiano del CLN y de la fase constituyente. Si los socialistas pretenden la legitimación institucional a través de la aprobación popular de la nueva ordenación y el libre enfrentamiento de los partidos, el MFA y los comunistas son defensores del principio eficaz-populista de las reformas sociales inmediatas (reforma agraria, nacionalizaciones, abandono de las colonias y depuración) y, con reservas comunistas, de la democracia directa y de los comités ${ }^{25}$.

Pero tal estrategia de legitimación, al ser tendencialmente la estrategia de una minoría basada en el riesgo, necesita no sólo y no tanto de persuasión gramsciana como de fuerza. Ha habido fuerza y asunción del riesgo (monopolio comunista de la Intersindical, confiscación y censura de la prensa, expropiación agraria acelerada, apropiación de los archivos políticos de la PIDE, suspensión de partidos), pero con efectos deletéreos sobre la cohesión del Gobierno civil-militar, abierto a menudo a socialistas y miembros del PPD, pero sujeto a continuas remodelaciones y caídas del poder. Al final la voluntad de riesgo no compensa, y el «viento del norte» o, en nuestro caso, el viento del sur -industrial y de peonaje- se calma con el enfrentamiento entre las diversas facciones de las Fuerzas Armadas ${ }^{26}$.

Así, el Partido Socialista, entre todos los partidos, se ha visto en primer lugar convertido irónicamente, en el objetivo elegido $\mathrm{y}$, posteriormente, en el beneficiario principal en el plano electoral de los ataques de la extrema izquierda civil y militar. En las elecciones de la Asamblea Constituyente de abril de 1975, convocadas mientras continúa el choque entre las diversas estrategias, los socialistas de Soares consiguen el 37,9 por 100 de los votos -un porcentaje más elevado que la DC en 1946-, distanciándose apreciablemente de los comunistas y de sus aliados del MDP. Se trata de una victo-

${ }^{25}$ En relación con las dos aproximaciones a la legitimación aplicadas respectivamente a la Grecia de Karamanlis y a Portugal, véase G. Pasquino, L'Instaurazione dei regimi democratici in Grecia e Portogallo, en «Il Mulino», 238, marzo-abril 1975, págs. 217-237. Pasquino distingue entre legitimación electoral y legitimación a través de la solución de los problemas.

${ }^{26}$ Las cosas podrían haber sido de otro modo pero queda el hecho de que a militares y comunistas les faltó calcular el «surplus» material e intelectual necesario para llevar adelante una estrategia arriesgada. Este es el punto a que se refiere Schmitter cuando habla de la dificultad de realizar un bloque histórico gramsciano al tiempo que se mantiene una revolución. Véase Schmitter, Historical Bloc Formation, cit. 
ria manifiesta sobre la adversaria estrategia de legitimación de la alianza comunista militar, pero una victoria que implica unos costes. El electorado socialista se revela muy heterogéneo, con sectores conservadores, inclinados hacia el PSP por su función garante durante el período más agitado de la transición y por las dificultades en que se encontraron las fuerzas de los partidos conservadores en los primeros meses. Por añadidura, tal y como pusieron de manifiesto las elecciones parlamentarias celebradas un año después, el número de electores socialistas disminuye en Lisboa, centro de prestigio para el partido, en los núcleos industriales al sur de la capital y entre los trabajadores de los latifundios meridionales -es decir, allí donde los comunistas cuentan con mayor fuerza, frecuentemente a niveles de mayoría absoluta. Dado el curso de la transición y las tendencias de los electores y de los partidos, es comprensible la decisión de Soares de formar un gobierno minoritario monocolor después de las elecciones de 1976. Empujado por la extrema izquierda y por el centro derecha a abrirse a las alas, el partido socialista tiene necesidad de conquistar espacio político a una izquierda de la que no se fía y que en 1976, a pesar de la derrota estratégica, se aproxima, entre el Partido Comunista y los grupos más o menos extraparlamentarios, a un considerable 20 por 100 del electorado, y a un centro derecha aún más consistente ( 40 por 100 de los votos) que podría comprometer las ya discutidas credenciales reformadoras. Una experiencia de gobierno sólo puede servir al equipo socialista para probar su capacidad efectiva de gobierno; también puede ser útil, dado el hecho de que gran parte de su prestigio internacional se debe al evidente apoyo moral y material de la socialdemocracia europea, para cubrir el crédito abierto por los otros partidos socialistas.

Pero, aunque comprensible, la ambiciosa opción socialista no perdura. En mi ensayo sobre Italia, Portugal y España ya había anticipado este desarrollo de la siguiente forma:

«El Partido (Socialista) carece de la capacidad de hegemonizar el centro político que la DC ha poseído en Italia, en la posguerra, gracias a la presencia de las estructuras organizativas de la Iglesia y de una cultura católica bien identificada, al aislamiento geográfico de los comunistas y a la poca entidad de las fuerzas que tenía a su derecha. Asimismo, la DC tampoco ha intentado ni podido gobernar sola. Antes o después las coaliciones portuguesas deberán ampliarse y esto sucederá aunque el Partido Socialista no se redimensione ni se fragmente $-\mathrm{y}$ siempre suponiendo que hechos imprevisibles no impongan soluciones subversivas. A pesar de las sospechas de Soares respecto de los comunistas, el Partido Socialista contiene sectores sensibles a los chantajes ideológicos de Cunhal y preocupados por la alteración en marcha de las reformas sociales más irreflexivas introducidas por los militares. Estas tensiones internas aparecieron claramente con ocasión del congreso nacional del partido el otoño pasado y de los conflictos en el seno del gobierno. En la otra banda, los socialistas tendrán dificultades para retener sus sectores conservadores ocasionales que ideológicamente todavía les pertenecen menos. Tampoco puede el Partido Socialista afrontar solo, aunque sea con 
la tutela de la CEE y con el estímulo de los grandes partidos hermanos, problemas de dependencia y de subdesarrollo económico, incomparablemente más arduos que los de españoles e italianos. Se replanteará así la necesidad de coaliciones ampliadas, que pueden contener la presión de los elementos más retrógrados de derecha y persuadir quizá al Partido Comunista — que propone ya alianzas de gobierno a los odiados socialistas- para llevar a cabo estrategias más posibilistas que las anteriores aunque este desarrollo requiera o no el apoyo de los sectores moderados de las Fuerzas Armadas, todavía en juego, volverán a producirse esquemas sincréticos de gobierno...» ${ }^{27}$.

La evolución más reciente confirma estas predicciones. Desde enero de este año, socialistas y CDS gobiernan formando una coalición de centro que -en la cuidadosa ponderación verbal de papeles partidistas, parlamentarios y de gobierno ${ }^{28}$ - trae a la mente acuerdos similares, hoy en vigor en España e Italia ${ }^{29}$. Pero la coalición no pone fin a una transición llevada a cabo prudentemente juntos con el fin de conseguir una recíproca legitimación, sino que, por el contrario, culmina un doble corte en el espectro de la legitimidad de partidos y coaliciones: a la izquierda (PCP) y a la derecha (Partido Social Democrático, ex PPD de Sa Carneiro). Por ello la coalición, impuesta a falta de otras posibilidades, debe tener una vida difícil. El que dicha coalición prefigure un porvenir sin perspectivas claras de alternativa, como sugeriría, es algo que consideraré después de haber discutido el caso griego.

Grecia. Mientras Portugal se aventura en el umbral de un juego de legitimación futura, que se revela sin salida, puede decirse que el juego griego, a la caída de los coroneles en julio de 1974, ha sido conducido tanto hacia el futuro como hacia el pasado. Si se observan analogías entre Grecia, España e Italia, en el sentido de que la transición griega revela en cuanto a opciones y contenidos institucionales un equilibrio entre continuidad y ruptura, conseguido incluso más rápidamente que en estos dos últimos países, existe, sin embargo, un aspecto notablemente diferente en lo que concierne a nuestra exposición sobre la legitimación; me refiero a la gestión de la transición, sincrética en España e Italia, gaullista en Grecia. A diferencia de la DC italiana y de la UCD española, el primer ministro Karamanlis y su agrupación partidista, Nueva Democracia, no tienen dificultad en monopolizar desde el principio las palancas del Gobierno y el proceso mismo de transición, manteniendo a distancia a la izquierda y a la extrema derecha sin hacerles concesiones significativas de tipo sincrético. Aunque esta estrategia se ha desarrollado hasta el presente con facilidad, hasta el punto de que la fase de transición se puede considerar concluida hace algún tiempo, queda claro que ello no significa que

${ }^{27}$ G. di Palma, Italia, Portogallo, Spagna, cit., pág. 58.

${ }^{28} \mathrm{La}$ coalición se presenta, en realidad, como un gobierno socialista con la participación de personalidades representativas del CDS. Como sucede frecuentemente en la Europa meridional, estas sutiles distinciones tienen su importancia.

${ }_{29}$ El ensayo fue escrito antes de la crisis de gobierno que ha marcado la ruptura de la alianza entre el PSP y el CDS (N. de R.). 
tengamos en Grecia un ejemplo de legitimación bien encarrilado. El gaullismo, aun siendo perfectamente compatible con los esfuerzos de legitimación «retroactiva-y-futura», es una estrategia que implica riesgo y enfrentamientos directos; y como el gaullismo de gestión se refleja después forzosamente en las especiales soluciones institucionales (más «extorsionadas» que negociadas), adecuadas para establecer el equilibrio continuidad-ruptura, es probable que ciertas dificultades institucionales surjan en un porvenir no muy lejano. Pero entendemos, es útil explicar el porqué de la estrategia griega, su contenido y gestión. El porqué parece, en primer término, en el hecho de que las fuerzas implicadas en la transición griega sean menos amplias o estén menos diversificadas y tengan menor credibilidad en lo que respecta a la capacidad de chantaje o a voluntad de reconocimiento que en los otros países, lo que permite, hasta cierto punto, no contar con ellas.

Para empezar, aparte el estilo gaullista, propio de la personalidad política de Karamanlis -estilo alimentado en su exilio parisino durante los años de la presidencia de De Gaulle-, el ofrecimiento «militar-civil» para que tomara las riendas del Gobierno Civil tiene puntos de contacto con la invitación «civilmilitar» dirigida a De Gaulle en 1958. La posibilidad y los alicientes de un experimento gaullista son favorecidos por la naturaleza de la crisis del régimen militar. La crisis de Chipre, desencadenada por parte griega por los mismos militares, no provoca, al contrario que en Portugal, una ruptura en las Fuerzas Armadas - $y$, desde luego, no por la izquierda - La única tímida ruptura en la veleidosa y abortiva revuelta militar de febrero de 1975 procede de la derecha, con el pretexto de la escasa agresividad de la diplomacia chipriota de Karamanlis y el resurgir del activismo de la izquierda. Todo esto significa dos cosas. Primeramente la situación griega ofrece poco o ningún espacio para una estrategia alternativa de ruptura total con el pasado y de establecimiento de un orden totalmente nuevo, del tipo, en suma, pretendido en Portugal por la extrema izquierda civil y militar. En segundo lugar el papel desempeñado por los círculos militares conservadores en la vuelta a formaciones civiles de Gobierno significa que las Fuerzas Armadas, así como importantes sectores civiles esperan si no un continuismo, sí, al menos, un Gobierno fuerte de ley y orden. Karamanlis puede muy bien responder a esta demanda en un contexto democrático sin tener que someterse a la hipoteca militar y sin convertir a las Fuerzas Armadas en un interlocutor privilegiado. Después de todo, el régimen de los coroneles, de siete años de duración, puede ser caracterizado como un régimen de excepción, no consolidado aún en sus instituciones, práctica ni principios. Este mismo hecho, el hecho, en otras palabras, de una experiencia competitiva aún existente en tiempos recientes, aunque haya sido traicionada y distorsionada repetidas veces, significa también que la nueva fase constituyente, a la caída del régimen de los coroneles, no requiere los delicados y complejos equilibrios entre reformas de alcance histórico y cooptación-conversión de las viejas fuerzas políticas, exigidos en España como consecuencia de cuarenta años de autoritarismo bien enraizado. En Grecia la fase constituyente puede ser gestionada por Karamanlis con mayor facilidad y con mejores posibilidades de marginar demandas discordantes. En resumen, si, de una parte, no hay espacio en Grecia para estrategias alternativas del tipo portugués, de 
otra, no existen presiones inmediatas hacia una «transición por transacción» de tipo español.

El Estado y la estrategia de las fuerzas de la izquierda refuerzan aún más las posibilidades para que las fuerzas de Karamanlis actúen solas. Los comunistas están divididos en dos partidos, el Partido Comunista de Grecia (KKE), considerado ortodoxo y prosoviético, que no tiene posibilidades de participación en el juego y el Partido Comunista del Interior (KKE Esoterikon) que, si bien es eurocomunista, carece de liderazgo y de la fuerza organizativa necesarios para conseguir prestigio internacional y visibilidad interior, liderazgo y organización de los que, no obstante su escasa clientela electoral, goza el partido español. La izquierda socialista, reorganizada en el nuevo Movimiento Socialista Panhelénico (PASOK), guiada con un estilo personalista por Andreas Papandreu, tiene escasas raíces tanto en la historia del socialismo europeo como en la tradición obrera del país, por ser un partido particularmente campesino y pequeño-burgués. Dadas sus preferencias por ideologías «mediterráneas» y de «dependencia» podría parecerse al pequeño PSP español de Tierno Galván, pero sus cuadros centrales prefieren al intelectualismo del PSP y a sus estrechos lazos con las organizaciones socialistas que encabeza un PSOE ${ }^{30}$, un antiintelectualismo autoritario de tipo nacionalpopulista y una política de presencia localista, reivindicativa y a veces de clientela. Si el Gobierno de Karamanlis no tiene razones especiales para abrirse hacia el PASOK, Papandreu tiene buenas razones para establecer las credenciales ideológicas del nuevo partido y sus ambiciones hegemónicas sobre el electorado de izquierdas, mediante una campaña frontal contra la política interior y exterior de Karamanlis y contra los remanentes del régimen militar.

En estas condiciones constitucionales y partidistas, Karamanlis tiende a aprovechar la ventaja táctica de su apariencia y de su prestigio de estadista en el exilio para consolidar rápidamente su control político. Las elecciones de noviembre de 1974 dan a Karamanlis y su partido una gran victoria popular. Más importante es que, como el sistema electoral favorece mucho a los partidos mayoritarios, es decir, a los que sobrepasan el 17 por 100 de los votos en todo el país, las elecciones ofrecen a Karamanlis el control absoluto de la asamblea y, con el consiguiente arresto del triunvirato que dirigió el régimen militar, la posibilidad de confirmarse como el único garante del orden, de la ley y de la estabilidad. Si añadimos a la victoria de Karamanlis el buen comportamiento electoral de la vieja Unión del Centro, dirigida ahora por George Mavros, las fuerzas conservadoras y moderadas tienen prácticamente el monopolio de la asamblea.

La estrategia de Karamanlis, a partir de la ley electoral que favorece a la mayoría, recuerda el intento frustrado del general Spinola de convocar elecciones presidenciales en los primeros vaivenes de la revolución portuguesa ${ }^{31}$,

${ }^{30}$ Efectivamente, el PSP y el PSOE acababan de fusionarse cuando estaba terminando la primera redacción de este artículo.

${ }^{31}$ Para establecer una comparación y para analizar muchos de los puntos tratados aquí, véase $\mathrm{G}$. Pasquino, L'instaurazione di regimi democratici, cit. Sin embargo, el análisis de Pasquino sobre las causas de la caída de los militares es muy diferente del mío. (Confróntese el suyo, Le Portugal: de la dictature corporatiste a la democratie socialiste, 
y se diferencia de los designios implícitos en la convocatoria del referéndum sobre la Ley de Reforma Política por parte del Gobierno de Suárez. Si, efectivamente, el resultado del referéndum sirve indirectamente para asegurar la función central de los sucesores reconocidos por Franco en la dirección de la transición, ello implica, además, un plan de reforma constitucional y, en consecuencia, una solicitud más expresa y formal de que el Gobierno negocie colectivamente con los representantes de los partidos los momentos sucesivos de la transición. Por el contrario, nada de todo esto está implícito en la convocatoria de las elecciones parlamentarias griegas, sobre todo después de los malos resultados electorales de la izquierda. Es decir, ya a partir de la adopción de la ley electoral y de la detención del triunvirato militar, Karamanlis ejecuta un plan suyo de reforma institucional; pero si el plan está realizado de tal forma que modere una ruptura respecto del régimen militar y de las ambigüedades, las manipulaciones electorales y la represión de los partidos del viejo régimen monárquico-parlamentario, a través de la búsqueda de un Gobierno democrático igualmente estable y fuerte, el plan es del todo suyo. Así, con la fuerza de la victoria electoral y del monopolio sobre un Parlamento reforzado por la ley electoral, Karamanlis convoca por sorpresa, a las tres semanas de las elecciones parlamentarias, el referéndum sobre la monarquía. El referéndum, con un 70 por 100 de los votos a favor de la República, lleva a un nuevo fortalecimiento del Gobierno tanto respecto de las izquierdas, sobrepasadas, como de las Fuerzas Armadas ${ }^{32}$. Que el referéndum represente un acontecimiento trascendente, por tratarse de la primera vez que fuerzas políticas conservadoras se alinean abiertamente del lado de la República, superando un obstáculo con raíces profundas en la historia griega, no quita que la operación sea obra del propio Karamanlis. Análogamente, la decisión de dar al país una nueva carta constitucional, después de pocos meses, es una decisión en gran medida gubernamental, y la elección de una Constitución gaullista es una opción unilateral a la que la izquierda se opone, pero sin presentar una clara batalla alternativa. Lo que asombra en el debate constitucional no es tanto la oposición de las izquierdas cuanto su aislamiento y su dificultad de plantear un diálogo, aunque sea muy crítico.

El éxito prolongado del montaje gaullista de Karamanlis no evita, sin embargo, la aparición de un último elemento perturbador. A pesar de los esfuerzos gubernamentales por pasar por encima de las posiciones de política exterior de la izquierda, a ésta la es fácil relacionar las dificultades del país en el plano internacional (NATO, Comunidad Europea, Chipre, Turquía y Estados Unidos) con los viejos problemas internos de la dependencia y el subdesarro$1 l{ }^{33}$, con el resultado de que las elecciones anticipadas, convocadas por el

Association Française de Science Politique, «La Sortie des Dictatures», Mesa Redonda, París, 6-7 de mayo de 1977.)

${ }^{32}$ En Italia, en el referéndum institucional de 1946, la República fue apoyada solamente por el 54 por 100 de los electores.

${ }_{33}$ Sobre la importancia del papel de la política exterior en la historia de Grecia, véase el más reciente de A. Pollis, Persistence, Cleavage and Change in Greece (comunicación preparada para un seminario en el Washington Center of Foreign Policy Research, Johns Hopkim University, 4 de mayo de 1977); P. J. Vatikiotis, Greece: A Political Essay (The 
Gobierno en noviembre de 1977, pretenden consolidar el apoyo popular antes de que sea más tarde, se traducen en un avance importante del PASOK. Si bien la mayoría relativa de los votos y la absoluta de escaños permanecen en manos del partido de Karamanlis, los buenos resultados obtenidos por el Partido Comunista ortodoxo, el crecimiento del Frente Nacional en la extrema derecha y el colapso de la Unión de Centro de Mavros socavan posteriormente el margen de acción del espectro conservador-moderado. Papandreu puede ahora compartir con Karamanlis ${ }^{34}$ la ventaja atribuida a los mayores partidos por la ley electoral.

Traducción: Santiago SÁnchez González

Washington Papers, 2, 8, Benerhy Hills and London, Sage Publications, 1974). Para un análisis equilibrado de los efectos políticos del desarrollo económico «dependiente» de Grecia, véase N. Mourelis, «Capitalism and Dictatorship in Post-war greece», en New Left Review, 96, marzo-abril 1976, págs. 57-80.

${ }^{34}$ La personalización que yo hago de la política griega tiene su base. Reflejo el hecho de que los partidos griegos, incluido el PASOK, siguen siendo muy personalistas y de que el carisma personal ha ejercido una influencia notable sobre el destino de los partidos y de los acontecimientos interpartidistas. 